\title{
A Comparative Study on Different Types of Premiums in Life Insurance Policies
}

\author{
Kutub Uddin, Md. Kaosar Uddin, Farhad Kadir and Rabindra Nath Mondal
}

\begin{abstract}
An insurance system is a mechanism for reducing the adverse financial impact of random events that prevents the fulfillment of reasonable expectations, i.e. Insurance is designed to protect against serious financial reversals that may result from random events intruding on the plans of individuals. The Life Insurance Company calculates the policy price with the intent to recover claims to be paid and administrative costs and to make a profit. The cost of insurance is determined using the Mortality Table calculated by Actuaries. The insurance companies receive premiums from the policy owner and invest them to create a pool of money from which to pay claims and finance the insurance company's operations. Rates charged for life insurance increase with the insured's age because statistically people are more likely to die as they get older. In this paper, we have discussed different types of insurance policies including expenses and its impacts on lives. We also discussed the annual premium rates of endowment plans, three-payment plans and six-payment plans. Matlab programming is used to calculate the premium rates.
\end{abstract}

Index Terms - Insurance, Net premium, Endowment assurance, Three-payment plan, Six-payment plan, Life annuities.

\section{INTRODUCTION}

Actuarial Science applies mathematical and statistical methods to finance, insurance particularly to risk assessment. Actuarial mathematics deals with the mathematics of uncertainty and risk [1]. Some key areas where actuarial mathematics is principally applied are mortality study, financial risk, ruin theory, credibility, etc. Basic ideas from calculus, linear algebra, numerical analysis, statistics, mathematical programming and economics will appear as a building block in models of insurance systems [2]. The face amount of the policy is normally the amount paid when the policy matures, although policies can provide greater or lesser amounts. The policy matures when the insured dies or reaches a specified age. The most common reason to buy a life insurance policy is to protect the financial interest of the owner of the policy in the event of the insured's demise [3]. Life insurance is a must for all and sundry who have a family to look after. Not withstanding this, the need is not equal for all. For rich people, it may be a luxury but for the low-income

Published on November 7, 2020.

Kutub Uddin, Department of Mathematics, University of Dhaka, Bangladesh.

Md. Kaosar Uddin, Department of Mathematics, University of Dhaka, Bangladesh.

Farhad Kadir, Department of Mathematics, University of Dhaka, Bangladesh.

Rabindra Nath Mondal, Department of Mathematics, Jagannath University, Bangladesh.

(corresponding e-mail: rnmonda171 @ yahoo.com) community, it is a must. Yet the later sections of the society are not convinced that they need it; the government and nongovernment organizations need.

The Life Insurance Company calculates the policy price with the intent to recover claims to be paid and administrative costs and to make a profit [4]. The cost of insurance is determined using the Mortality Table calculated by Actuaries. The insurance companies receive the premiums from the policy owner and invest them to create a pool of money from which to pay claims and finance the insurance company's operations [5]. Rates charged for life insurance increase with the insured's age because statistically people are more likely to die as they get older. Since the adverse selection can have a negative impact on the financial results of the insurer, the insurer investigates each proposed insured beginning with the application which becomes a part of the policy [6]. Lack of insurance can contribute to inequality in society as a whole and which has a direct effect on the economic growth of any country. Life insurance companies, selling agents, NGOs, and the Government should take this issue together like a challenge equally. However considering the fact that number of people with low income far exceeds those with higher incomes, therefore low premium life insurance policies with no-frills can also be remunerative to the selling agents and the Life Insurance companies, as low margins of profit would be more than offset by the high volumes of policies sold (Chaudhury, 1994). The calculation has been assessed from the actuarial tables [7]. Based on the U. S. Life Tables: 1979-81, Actuarial Study No. 96. Need in such awareness should be created on both sides, life insurance companies, their selling agents and the concerned strata of people with low incomes. Here the regulatory bodies, Government and non-Government Organizations can play important roles.

Net premiums are based on interest and mortality only (expenses are ignored) and would be just sufficient to meet claims on policies as they become due if the mortality experienced by the group that assumed in the premium calculations, and if the rate of interest earned on investment of premiums were also that assumed in the premiums calculations. Office premiums, on the other hand, include expenses for office management. It may also include a margin to cover contingencies, profits, etc. In the case of office premiums, the mortality experienced by the assured lives may not be the same as assumed in the premium calculation, and the rate of interest earned may not be equal to the assumed rate of interest. In fact, mortality, interest, and expenses assumed in the office premium contain certain margins. The premiums are paid by the assured life for receipt of a benefit payable by the insurer. If expenses are ignored the present value of the premiums must be equal to 
the present value of the sum assured. In this paper, we discussed different types of insurance policies including expenses. We discussed the annual premium rates of both endowment plans and three-payment plans. We used mathematical programming MatLab to calculate the premium rates.

\section{A. Notations}

It is customary to use the notation for level annual premiums. The following notations are generally used:

$P_{x: \bar{n} \mid}^{1}=$ annual premium for an $n$-year temporary assurance of 1 on the life aged $x$;

$P_{x: \bar{n} \mid}=$ annual premium for an $n$-year endowment assurance of 1 on the life aged $x$;

$t P_{x}=$ annual premium limited to $t$ payments for a whole life assurance of 1 on the life aged $x$;

$t P_{x: \bar{n} \mid}=$ annual premium limited to $t$ payments for an endowment assurance of 1 on the life aged $x$;

$P_{x}=$ annual premium for a whole life assurance of 1 on the life aged $x$.

\section{MAthematical Formulations OF Net PREMiUmS}

\section{A. Whole Life Assurance}

Let $P_{x}$ be the annual premium for a whole life assurance of 1 on the life aged $x$. The premiums continue to be paid until the life assured dies. The value of the premiums would, therefore, be equal to $P_{x} \ddot{a}_{x}$. We also know that the value of the whole life sum assured of 1 is $A_{x}$. Therefore, we get:

$$
\begin{gathered}
P_{x} \ddot{a_{x}}=A_{x} \\
P_{x}=\frac{A_{x}}{\ddot{a}_{x}}=\frac{M_{x} / D_{x}}{N_{x} / D_{x}}=\frac{M_{x}}{N_{x}}
\end{gathered}
$$

\section{B. Temporary Assurance}

The value of temporary assurance of 1 on a life aged $x$, as we know, is $A_{x: \bar{n} \mid}^{1}$. The present value of the premiums is $P_{x: \bar{n} \mid}^{1} \ddot{a}_{x: \overline{n \mid}}$. Hence,

$$
\begin{gathered}
P_{x: \bar{n} \mid}^{1} \ddot{a}_{x: \bar{n} \mid}=A_{x: \bar{n} \mid}^{1} \\
\operatorname{or} P_{x: \bar{n} \mid}^{1}=\frac{A_{x: \bar{n} \mid}^{1}}{\ddot{a}_{x: \bar{n} \mid}}=\frac{\left(M_{x}-M_{x+n}\right) / D_{x}}{\left(N_{x}-N_{x+n}\right) / D_{x}}=\frac{\left(M_{x}-M_{x+n}\right)}{N_{x}-N_{x+n}}
\end{gathered}
$$

\section{Endowment Assurance}

The value of an $n$-year endowment assurance on 1 of the life aged $x$ is $A_{x: \bar{n} \mid}$.

The value of the premiums is $P_{x: \bar{n} \mid} \ddot{a}_{x: \bar{n} \mid}$. Therefore:

$$
P_{x: \bar{n} \mid} \ddot{a}_{x: \bar{n} \mid}=A_{x: \bar{n} \mid}
$$

or $P_{x: \bar{n} \mid}=\frac{A_{x: \bar{n} \mid}}{\ddot{a}_{x: \bar{n} \mid}}=\frac{\left(M_{x}-M_{x+n}+D_{x+n}\right) / D_{x}}{\left(N_{x}-N_{x+n}\right) / D_{x}}=\frac{M_{x}-M_{x+n}+D_{x+n}}{N_{x}-N_{x+n}}$

\section{Limited-Premiums Payments}

If premiums are paid for a limited period, say $t$ year, the present value of all the premiums is $P_{x} \ddot{a}_{x: \bar{t} \mid}$. Hence, we get:

$$
\begin{gathered}
P_{x} \ddot{a}_{x: \bar{t} \mid}=A_{x} \\
\text { or } P_{x}=\frac{A_{x}}{\ddot{a}_{x: \bar{t} \mid}}=\frac{M_{x} / D_{x}}{\left(N_{x}-N_{x+t}\right) / D_{x}}=\frac{M_{x}}{N_{x}-N_{x+n}}
\end{gathered}
$$

\section{E. Temporary Assurance}

For temporary assurance, we get the equation of payments if premiums are limited to $t$ payments and the term is in years, as follows:

$$
\begin{gathered}
P_{x: \bar{n} \mid}^{1} \ddot{a}_{x: \bar{n} \mid}=A_{x: \bar{n} \mid}^{1} \\
P_{x: \bar{n} \mid}^{1}=\frac{A_{x: \bar{n} \mid}^{1}}{\ddot{a}_{x: \bar{n} \mid}}=\frac{\left(M_{x}-M_{x+n}\right) / D_{x}}{\left(N_{x}-N_{x+n}\right) / D_{x}}=\frac{\left(M_{x}-M_{x+n}\right)}{N_{x}-N_{x+n}}
\end{gathered}
$$

\section{F. Endowment Assurance}

If the premium payment is $\mathrm{t}$ years and the term of the assurance is n years, as before, the equation of payment is as follows:

$$
\begin{gathered}
P_{x: \bar{n} \mid} \ddot{a}_{x: \bar{t} \mid}=A_{x: \bar{n} \mid} \\
\text { or } P_{x: \bar{n} \mid}=\frac{A_{x: \bar{n} \mid}}{\ddot{a}_{x: \bar{t} \mid}}=\frac{\left(M_{x}-M_{x+n}+D_{x+n}\right) / D_{x}}{\left(N_{x}-N_{x+t}\right) / D_{x}}=\frac{M_{x}-M_{x+n}+D_{x+n}}{N_{x}-N_{x+t}}
\end{gathered}
$$

\section{G. Premiums Payable m Times a Year}

In the above cases, we have assumed that premiums are payable yearly. In practice, however, the premiums are payable more frequently than yearly. In the case where premiums are payable $\mathrm{m}$ times a year, the following approximate formula may be used. Derivation of the formula which is outside the scope of the book is not given.

$$
\begin{gathered}
\quad P_{x: \bar{n} \mid}^{(m)}=\frac{P_{x: \bar{n} \mid}}{1-\frac{m-1}{2 m}\left(P_{x: \bar{n} \mid}^{1}+d\right)} \\
\text { and } P_{x}^{(m)}=\frac{P_{x}}{1-\frac{m-1}{2 m}\left(P_{x}+d\right)}
\end{gathered}
$$

Once $P_{x: \overline{n \mid}}$ are known, $P_{x: \bar{n} \mid}^{(m)}$ can be calculated; and $P_{x}$ are known, $P_{x}^{(m)}$ can be calculated. However, for practical purposes more simple method is adopted for the calculation of premiums payable other than yearly.

\section{H. Double Endowment Assurance}

A double endowment is one under which the sum assured at maturity is twice the sum assured payable at previous death. The annual premium, $\mathrm{P}$, for an $n$-year double endowment assurance providing 2 on survival and 1 in the event of death is given by:

$$
P_{x} . \ddot{a}_{x: \bar{n} \mid}=A_{x: \bar{n} \mid}^{1}+2 A_{x: \bar{n} \mid}
$$




$$
P_{x}=\frac{A_{x: \bar{n} \mid}^{1}+2 A_{x: \bar{n} \mid}}{\ddot{a}_{x: \bar{n} \mid}}=\frac{\frac{\left(M_{x}-M_{x}+n\right)}{D_{x}}+\frac{2 D_{x+n}}{D_{x}}}{\left(N_{x}-N_{x+n}\right) / D_{x}}=\frac{M_{x}-M_{x+n}+2 D_{x+n}}{N_{x}-N_{x+n}}
$$

\section{RESULTS AND COMPARATIVE STUDY}

\section{A. Insurance Models Including Expenses}

A more realistic view of the insurance business includes provision for expenses. The profit for the company can also be included here as an expense. The common method used for the determination of the expenses loaded premium is a modification of the equivalence principle. According to the modified equivalence principle, the gross premium $\mathrm{P}$ is set to that on the policy issue date the actuarial present value of the benefit plus expenses is equal to the actuarial present value of the premium income. The premium is usually considered to be constant. Under these assumptions, it is fairly easy to write a formula to determine P. Three elements which are to be taken into consideration while designing a product and pricing the product, i.e. to calculate the premiums are:

1) Rate of mortality.

2) Expenses incurred by the life insurance business.

3) Rate of return on investment.

\section{B. Product Design}

As per art. 39 of the insurance rule 1938, the limitation of expenses of management (including commission and any other remuneration for procreation of business) in any calendar year is an amount not exceeding $90 \%$ of the 1 st year premium and $15 \%$ of renewal premium for a life insurance company whose year of operation are 10 years or more and terms of the insurance policy not less than 12 years.

\section{Annual Premium of an Endowment Plan}

We calculate the annual Premium of a product which provides the benefit of Tk.1000 on survival up to maturity and Tk.1000 on death before maturity. This type of plan is called the endowment plan. If we consider the term of the policy to be $n$ years and we want to calculate the annual premium for a person aged $(x)$ if $P$ is the annual premium then,

$$
\begin{aligned}
& \text { Value of death benefit is } 1000 A_{x: \bar{n} \mid}^{1} \\
& \text { Value of survival benefit is } 1000 A_{x: \bar{n}} \frac{1}{}
\end{aligned}
$$

Hence the present value of the premium is $P a_{x: \bar{n} \mid}$. Considering the expenses following the rule of insurance act we have:

$$
\begin{gathered}
P \ddot{a}_{x: \overline{n \mid}}=1000 A_{x: \overline{n \mid}}^{1}+1000 A_{x: \bar{n} \mid}+0.75 \mathrm{P}+0.15 P \ddot{a}_{x: \bar{n} \mid} \\
\text { or } P=\frac{1000\left(M_{x}-M_{x+n}+D_{x+n}\right)}{0.85\left(N_{x}-N_{x+n}\right)-.75 D_{x}}
\end{gathered}
$$

\begin{tabular}{|c|c|c|c|}
\hline \multicolumn{2}{|c|}{$4 \%$ interest } & \multicolumn{2}{|c|}{$6 \%$ interest } \\
\hline Age & Premiums & Age & Premiums \\
\hline 20 & 62.1026 & 20 & 52.6496 \\
\hline 21 & 62.1169 & 21 & 52.6637 \\
\hline 22 & 62.1246 & 22 & 52.6786 \\
\hline 23 & 62.1317 & 23 & 52.6948 \\
\hline 24 & 62.1385 & 24 & 52.7142 \\
\hline 25 & 62.1503 & 25 & 52.7376 \\
\hline 26 & 62.1685 & 26 & 52.7659 \\
\hline 27 & 62.1942 & 27 & 52.8000 \\
\hline 28 & 62.2293 & 28 & 52.8413 \\
\hline 29 & 62.2747 & 29 & 52.8885 \\
\hline 30 & 62.3304 & 30 & 52.9443 \\
\hline 31 & 62.3982 & 31 & 53.0089 \\
\hline 32 & 62.4810 & 32 & 53.0826 \\
\hline 34 & 62.5791 & 34 & 53.1672 \\
\hline 35 & 62.6932 & 35 & 53.2620 \\
\hline
\end{tabular}

The annual premium table per Tk.1000 for an insurance policy of term 15 years plan for both at $4 \%$ interest rate and $6 \%$ interest rate using MatLab programming is given below.
TABLE 1:15 YEARS PLAN

\section{Annual Premium for a Three-Payment Plan}

In three payments plan survival benefit is given at 3 stages of the total term of the policy. If the term of the policy is 12 years then we may consider that $25 \%$ of the sum assured is provided after the expiry of 4 years, $25 \%$ of the sum assured is provided after the expiry 8 years and finally, $50 \%$ of the sum assured is provided at the end of the term i.e. after 12 years as survival benefit. So, the Mathematical formulation for a three payment plan, where the basic sum assured is Taka 1000 using the commutation function $M x$, $D x, N x$ for $n$ years and for a person aged $x$ is:

Value of survival benefit is $1000 A_{x: n \mid}$.

The present value of the premium is $P a_{x: \bar{n} \mid}$. Considering the expenses following the rule of insurance act we have:

$$
P=\frac{1000\left(M_{x}-M_{x+n}\right)+250 D_{x+4}+250 D_{x+8}+500 D_{x+12}}{0.85\left(N_{x}-N_{x+n}\right)-0.75 D_{x}}
$$

The annual premium table per Tk.1000 of a threepayment plan for a term of 12 years for both at $4 \%$ interest rate and $6 \%$ interest rate using MatLab programming is given below.

\begin{tabular}{cccc}
\multicolumn{4}{c}{ TABLE 2: 12 YEARS PLAN } \\
\hline & 4\% interest & \multicolumn{2}{c}{ 6\% interest } \\
\hline Age & Premiums & Age & Premiums \\
\hline 20 & 95.1564 & 20 & 89.3060 \\
21 & 95.1732 & 21 & 89.3238 \\
22 & 95.1844 & 22 & 89.3431 \\
23 & 95.1934 & 23 & 89.3647 \\
24 & 95.2052 & 24 & 89.3907 \\
25 & 95.2240 & 25 & 89.4220 \\
26 & 95.2536 & 26 & 89.4602 \\
27 & 95.2928 & 27 & 89.5062 \\
28 & 95.3449 & 28 & 89.5610 \\
29 & 95.4103 & 29 & 89.6234 \\
30 & 95.4916 & 30 & 89.6966 \\
31 & 95.5886 & 31 & 89.7814 \\
32 & 95.7066 & 32 & 89.8779 \\
34 & 95.8436 & 34 & 89.9881 \\
35 & 96.0025 & 35 & 90.1110 \\
\hline
\end{tabular}

The annual premium table per Tk.1000 of a threepayment plan for a term of 15 years for both at $4 \%$ interest rate and $6 \%$ interest rate using MatLab programming is given below. 
TABLE 3:15 YEARS PLAN

\begin{tabular}{cccc}
\hline & 4\% interest & \multicolumn{2}{c}{$6 \%$ interest } \\
\hline Age & Premiums & Age & Premiums \\
\hline 20 & 79.4984 & 20 & 76.1553 \\
21 & 79.5277 & 21 & 76.1845 \\
22 & 79.5569 & 22 & 76.2177 \\
23 & 79.5886 & 23 & 76.2557 \\
24 & 79.6270 & 24 & 76.3005 \\
25 & 79.6757 & 25 & 76.3518 \\
26 & 79.7387 & 26 & 76.4114 \\
27 & 79.8161 & 27 & 76.4811 \\
28 & 79.9117 & 28 & 76.5632 \\
29 & 80.0256 & 29 & 76.6556 \\
30 & 80.1587 & 30 & 76.7606 \\
31 & 80.3110 & 31 & 76.8787 \\
32 & 80.4873 & 32 & 77.0107 \\
34 & 80.6897 & 34 & 77.1599 \\
35 & 80.9217 & 35 & 77.3260 \\
\hline
\end{tabular}

\section{E. Annual Premium for a Six-Payment Plan}

In three payments plan survival benefit is given at 3 stages of the total term of the policy. If the term of the policy is 12 years then we may consider that $14.286 \%$ of the sum assured is provided after the expiry of 2 years, $14.286 \%$ of the sum assured is provided after the expiry 4 years, this will be continued till 10 years in a consecutive 2 years gape and finally, $28.572 \%$ of the sum assured is provided at the end of the term i.e. after 12 years as survival benefit. So, the Mathematical formulation for a three payment plan, where the basic sum assured is Tk 1000 using the commutation function $M x, D x, N x$ for $n$ years and for a person aged $x$ is:

Value of survival benefit is $1000 A_{x: n \mid}:$.

The present value of the premium is $P a_{x: \bar{n} \mid}$. Considering the expenses following the rule of insurance act we have:

$$
\begin{gathered}
1000\left(M_{x}-M_{x+n}\right)+(7143 / 50) D_{x+2}+(7143 / 50) D_{x+4}+ \\
P=\frac{(7143 / 50) D_{x+6}+(7143 / 50) D_{x+8}+(7143 / 50) D_{x+10}+(7143 / 25) D_{x+12}}{0.85\left(N_{x}-N_{x+n}\right)-0.75 D_{x}}
\end{gathered}
$$

The annual premium table per Tk.1000 of a six-payment plan for a term of 12 years for both at $4 \%$ interest rate and $6 \%$ interest rate using MatLab programming is given below.

TABLE 4:12 YEARS PLAN

\begin{tabular}{cccc}
\hline \multicolumn{2}{c}{ 4\% interest } & \multicolumn{2}{c}{ 6\% interest } \\
\hline Age & Premiums & Age & Premiums \\
\hline 20 & 100.3216 & 20 & 96.5921 \\
21 & 100.3391 & 21 & 96.6123 \\
22 & 100.3517 & 22 & 96.6348 \\
23 & 100.3634 & 23 & 96.6601 \\
24 & 100.3789 & 24 & 96.6905 \\
25 & 100.4030 & 25 & 96.7275 \\
26 & 100.4391 & 26 & 96.7723 \\
27 & 100.4868 & 27 & 96.8260 \\
28 & 100.5494 & 28 & 96.8895 \\
29 & 100.6273 & 29 & 96.9617 \\
30 & 100.7233 & 30 & 97.0464 \\
31 & 100.8376 & 31 & 97.1444 \\
32 & 100.9760 & 32 & 97.2554 \\
34 & 101.1358 & 34 & 97.3814 \\
35 & 101.3197 & 35 & 97.5221 \\
\hline
\end{tabular}

The annual premium table per Tk.1000 of a six-payment plan for a term of 15 years for both at $4 \%$ interest rate and $6 \%$ interest rate, using MatLab programming is given below.
TABLE 5: 15 YEARS PLAN

\begin{tabular}{cccc}
\hline & 4\% interest & \multicolumn{2}{c}{$6 \%$ interest } \\
\hline Age & Premiums & Age & Premiums \\
\hline 20 & 83.7990 & 20 & 82.3565 \\
21 & 83.8289 & 21 & 82.3880 \\
22 & 83.8595 & 22 & 82.4242 \\
23 & 83.8936 & 23 & 82.4656 \\
24 & 83.9353 & 24 & 82.5145 \\
25 & 83.9888 & 25 & 82.5710 \\
26 & 84.0576 & 26 & 82.6368 \\
27 & 84.1426 & 27 & 82.7137 \\
28 & 84.2476 & 28 & 82.8038 \\
29 & 84.3726 & 29 & 82.9053 \\
30 & 84.5188 & 30 & 83.0210 \\
31 & 84.6864 & 31 & 83.1514 \\
32 & 84.8809 & 32 & 83.2968 \\
34 & 85.1035 & 34 & 83.4606 \\
35 & 85.3577 & 35 & 83.6432 \\
\hline
\end{tabular}

We have seen that the premium rate charged by MetLife, and different life insurance companies like Delta Life Insurance, National Life Insurance, etc. don't exactly match what we have calculated using MatLab programming. This may be due to the following reasons:

1) Since we haven't got any information about the calculation of the premium rates from different existing companies.

2) The rate of interest assumed by us in the calculation of the premium rate is higher than what has been assumed by these companies.

3) Expenses loaded in the premium determination formula are higher than what has been allowed in the insurance rule.

4) A combination of both the above reasons.

But above all, one of our experiments has been approximately matched with the basic annual premiums which have been provided by the American life insurance company (MetLife) for 15 years three-payment plan for 1000tk FA.

TABLE 6: 15 YEARS PLAN COMPARISON

\begin{tabular}{ccc}
\hline Age & $\begin{array}{c}\text { 15-Yr. 3PPP } \\
\text { (MetLife) }\end{array}$ & $\begin{array}{c}\text { 15-Yr. 3PPP } \\
\text { (Experiment) }\end{array}$ \\
\hline 20 & 79.20 & 79.4984 \\
21 & 79.30 & 79.5277 \\
22 & 79.30 & 79.5569 \\
23 & 79.40 & 79.5886 \\
24 & 79.40 & 79.6270 \\
25 & 79.50 & 79.6757 \\
26 & 79.60 & 79.7387 \\
27 & 79.60 & 79.8161 \\
28 & 79.80 & 79.9117 \\
29 & 79.90 & 80.0256 \\
30 & 80.00 & 80.1587 \\
31 & 80.20 & 80.3110 \\
32 & 80.40 & 80.4873 \\
34 & 80.60 & 80.6897 \\
35 & 80.80 & 80.9217 \\
\hline
\end{tabular}

\section{DISCUSSION}

In this paper, we have focused on how to calculate the annual premium by using MatLab programming, and broadly described the history of the insurance policy along with its classification to achieve how we exactly reach there to conduct business in dynamic portion to provide a bilateral comfortable business relationship between consumers and 
insurance companies. There is also a cryptic representation of annuity which is the initial requirement to calculate the annual premium, without the substantive equation of annuity there is no hope to find any types of premium. Its classification such as the immediate annuity, annuity due, deferred annuity, deferred immediate annuity gives us a lot of acknowledgment to construe the main formulae of the premium to reckon the net annual premium which is sorely demanding in this absurd world to confirm people's lives in a stable position to reduce their imminent disaster. Meanwhile, there is some sort of topic of assurance to reinforce for deriving a standard formula for defining a healthy equation by which it is pretty much sure to forecast a precise measurement after the fixed age $(x)$. Without this learning assurance, it is quite impossible to submit an acceptable estimation to satisfy the customer enough to decide whereas they really want to open an account or not. In this portion, we don't obliviate to point out the commutation functions which is ineluctable to form mathematical modeling of life insurance policies and that provides us conducive result of the annual premiums. By the ongoing processing, we are here, in which we have to concentrate our research subject 'premium', firstly narrating the basic concept of what is actually defined by the term premium and how exactly we can comprehend this term along with its categorization. In addition to this, we represent the formulae for reckoning our desired annual premium of an endowment plan, the annual premium for a three-payment plan, the annual premium for six-payment plan, the annual premium for twelve-payment plan, which will be elusive if we can't have these formulae to estimate these annual premiums seemly.

In this work, we have presented how one can apply mathematical programs to calculate the annual premiums of various insurance policies. It is quite difficult to get the agespecific premium rates but by the coding mathematical program rather than MatLab programming, that's why we give merely effort to how we can easily get the premium rates for different insurance policies for a person aged $(x)$ and for a term of the policy of $n$ years in a customized way by applying MatLab programming. It is found that the life expectancy of the insured population is more than the actual population, which means insurance companies are charging more premium rates than what they should charge. In the present study, we have discussed how to evaluate the premium of different assurance plans such as whole life assurance, temporary assurance, endowment assurance etc. We have calculated the premium for different life insurance policies like an endowment assurance plan, three-payment plan, six-payment plan, twelve-payment plan, and micro-life insurance policy at $4 \%$ interest and $6 \%$ interest rate using MatLab Programming. In the beginning, different commutation function has been evaluated which are further used to calculate the premium of a person aged $(x)$ for an insurance policy of term $n$ years, based on Actuarial function at $4 \%$ and $6 \%$ interest for 1979-81 USA. Then these functions are used to evaluate the premium of a person using MatLab programming.

We have calculated the annual premium for an $n$-year endowment assurance of the life aged $(x)$, where the basic sum assured is Tk.1000. We also calculated the annual premium for a three-payment plan. The basic sum assured for all this policy is TK.1000. Then we have given a tabular form of premium rates for these policies and we have also compared it with the premium rates of some existing companies like American Life Insurance Company, Delta Life Insurance Company, and Popular Life Insurance Company, etc. We have found that the premium rates of some of these companies (Metlife) are approximately the same as what we have computed.

\section{CONCLUSION}

In this paper, we have discussed different types of insurance policies including expenses. We also discussed the annual premium rates of endowment plans, threepayment plans and six-payment plans at $4 \%$ interest and $6 \%$ interest rate by using MatLab Programming.

In the beginning, different commutation function has been evaluated which are further used to calculate the premium of a person aged $(x)$ for an insurance policy of term $n$ years. The present study shows that the premium rates of some of the companies are approximately the same as what we have computed. The rate of interest assumed by us in the calculation of the premium rate is sometimes higher than what has been assumed by these companies. Expenses loaded in the premium determination formula are higher than what has been allowed in the insurance rule or, a combination of both the above reasons.

The three-payment plan is a very popular life insurance plan. In a three-payment Life Insurance Plan of term 12 years the insurer pays premium after every 4 years. On the continuation of three-payment plan, we have proposed sixpayment plan for the various interest rate. It is seen that customers will be more interested to buy a six-payment plan rather than buying a three-payment. This is because if the term of the policy is 12 years then in a six-payment plan customer will get some part of his sum assured at the end of every 2nd year; on the other hand, in a three-payment plan the customer will get some part of his sum assured after every four years. At the same, it will be easier for the company to convince people to buy a six-payment plan rather than to buy a three-payment plan. It is found that if the interest rate is increased than the net annual premiums, it will be decreased chronically in the case of an endowment plan, three- payment plan, six -payment plan, Therefore, we can predict the idea that it is very conducive for the business holder to render their service before the client makes them satiate with announcing more interest rather than put it into lower interest.

\section{REFERENCES}

[1] Bowers, Gerber, Hickman, Jones and Nesbitt, [1997], Actuarial Mathematics, Published by the Society of Actuaries, London.

[2] Dixit, S.P. Mondi, C.S. and Joshi, R.V. [2002], Mathematical Basis of Life Assurance, India.

[3] Uddin, M.S., [1999], an Introduction to Actuarial and Financial Mathematics, 1st Edition.

[4] Ali, K. M. M., [2004], Poverty Alleviation and need for Mutual Micro Insurance for the Poor, Insurance Journal; Volume: 55, July.

[5] Alma, S., [1993], Rural Insurance in India-its Diverse Uses, Insurance Journal; Volume: 44, June. 
[6] Zima, P and Brown, R. I., [2005], Theory and Problems of Mathematics of Finance, 2nd Edition.

[7] Alice Wade, A. S. A, [1986], Actuarial Tables Based on the U. S. Life Tables: 1979-81, Actuarial Study No. 96.

[8] Anderson, IL. And Dow, LB, [1991], Actuarial Statistics Vol. II, Cambridge University Press.

[9] Benjamin, B. [1971], the Analysis of Mortality and other Actuarial Statistics, Cambridge University Press.

[10] Day, J.G. and Jamison, A.T., [1993], Institutional Investment, Oxford University Press.

[11] Donald, D.W.A. [2016]. Compound Interest and Annuities-Certain, Cambridge University Press.

[12] Fisher, F. and Young. [1965]. Actuarial Practice of Life Assurance, Cambridge University Press.

[13] Freeman, H. [2016]. Actuarial Statistics, 1st edition, Cambridge University Press.

[14] Hooker. RF. and Longley-Cook. L.H. [2007]. Life and other Contingencies Cambridge University Press.

[15] Institute of Actuaries, [2020]. Actuarial Tables for Examination Purposes Cambridge University Press.

[16] Rose. H.B. [1966]. The Economic Background to Investment, Cambridge University Press.

[17] Hafiz G.A.S, Islam, S and Chowdhury, J.A., [1995], Life Insurance Business in Bangladesh: An evaluation. Insurance Journal; Volume: 47.

[18] Chaudhary, S.A., [1994], Life Insurance in Bangladesh-An Insurer's View, Insurance Journal; Volume: 46, June. 